
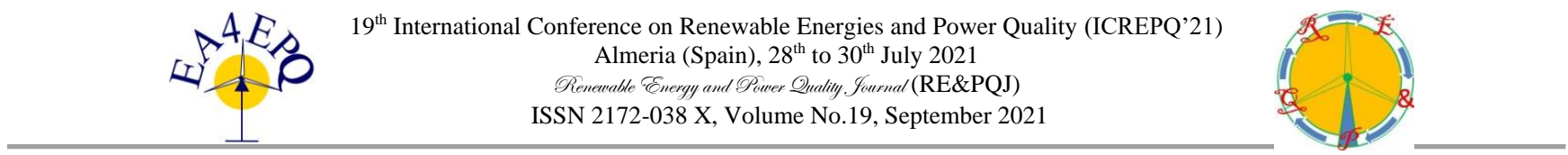

\title{
Wind energy system in Ambocas-Ecuador: distributed generation and energy quality
}

\author{
O. Cabeza-Gras ${ }^{1}$ and V. Jaramillo-García ${ }^{2}$ \\ ${ }^{1}$ Department of Physics and Earth Sciences \\ University of Coruña \\ Campus da Zapateira s/n. E-15071 A Coruña (Spain) \\ ${ }^{2}$ Electrical Engineering. Faculty of Engineering. \\ Universidad Laica Eloy Alfaro de Manabí (ULEAM) \\ Manta, Manabí (Ecuador)
}

Phone:+0034 981 167000, e-mail: oscar.cabeza@udc.es, fernando.jaramillo@uleam.esdu.ec

\begin{abstract}
In this communication we present the construction of a wind farm, WF, with $10 \mathrm{MW}$ of nominal power. This WF will increase the quantity and quality of electricity in the area of Ambocas, Loja, Ecuador, strengthen a system with many voltage drops. The place chosen is ideal, because it is long from population, in a hill side near an existing road. Wind is persistent and has a constant orientation all along the year. The generated power will be connected with the electricity system in the Portovelo Substation, which is about $12 \mathrm{~km}$ from the WF site. We have calculated the expected electricity production all along the year taking into account all important data to simulate successfully the WF operation in real conditions. We have also modelled the interconnexion of the WF with the substation and its effect in the $69 \mathrm{kV}$ bar. Finally, a brief economical analysis of the project gives an annual average profit higher than 3.5 USD million without taxes, while the inversion would be cancelled in less than 5 years of the 20 ones planned for the WF in full operation.
\end{abstract}

Key words. Wind energy, wind farm, electricity, distributed generation.

\section{Introduction}

Wind energy is the non-conventional renewable energy that has had the highest development among all types. It has been introduced in the electrical generation mix of many countries, and increasing to the future [1] Thus, in present European Union produces about a $15 \%$ of all electrical energy from wind. Among all EU countries, six of them have that percentage above 20\%: Denmark, Germany, Ireland, Portugal, United Kingdom and Spain [2]. Due to its scalability, wind technology is a very good solution also locally, especially for windy areas, far from distribution centres. In addition, the MW.h produced with wind is cheaper than with nearly any other alternative system.
In addition, wind energy does not produce any residues, nor solid, liquids or gas. A wind farm can be installed carefully in ecosystems without danger for it while producing energy (except for some birds, which impact must be studied independently). Obviously, wind energy contributes to reduction of greenhouse gases and is a real solution for future electrical generation [3]. Another advantage of wind is that allows to decentralise energy generation, giving place to a bidirectional flux of energy with dynamic behaviour. This new paradigm will open doors to democratization of energy generation [4].

Thus, installation of a wind farm could be the optimal solution to solve the electricity quality problem in Ambocas area, Loja district (Ecuador). In the Altiplano Orense, where the area is placed, both quality of power supply and product quality are deficient. Part of the problem is because the electrical bar of $69 \mathrm{kV}$ in the Portovelo electrical substation, there is actually a voltage regulation of minus $12 \%$. In addition, this last is about 60 $\mathrm{km}$ far from the Sistema Nacional de Transmisión (SNT). The area has a high energy consumption, both from industry as for residence. The primary demand is actually about $30 \mathrm{MW}$ of power, but it is planned the construction of a new industrial pole to process minerals, with power demand of about $20 \mathrm{MW}$ more. Thus, in a near future the actual problems with electricity quality will increase if do not generate electricity near the optimal charge point for the area, which includes cantons of Piñas, Portovelo, Atahulapa y Zaruma. This will require the detailed study of permanent and dynamic energy consumption, including interconnection with the distribution station [5]. 


\section{Wind farm location}

The wind farm (WF) would be located in Cerro de Ambocas, border between provinces of El Oro and Loja in Ecuador. Using ARCGIS-ESRI software we obtain its geographical coordinates: $\mathrm{x}=663310,57$ and $\mathrm{y}$ $=9584320,47$ WGS 84 UTM, 17S Zone, and average height above see level of $1300 \mathrm{~m}$. We have designed a wind farm with six mills $200 \mathrm{~m}$ apart each other along an existing road, as shown in Figure 1:
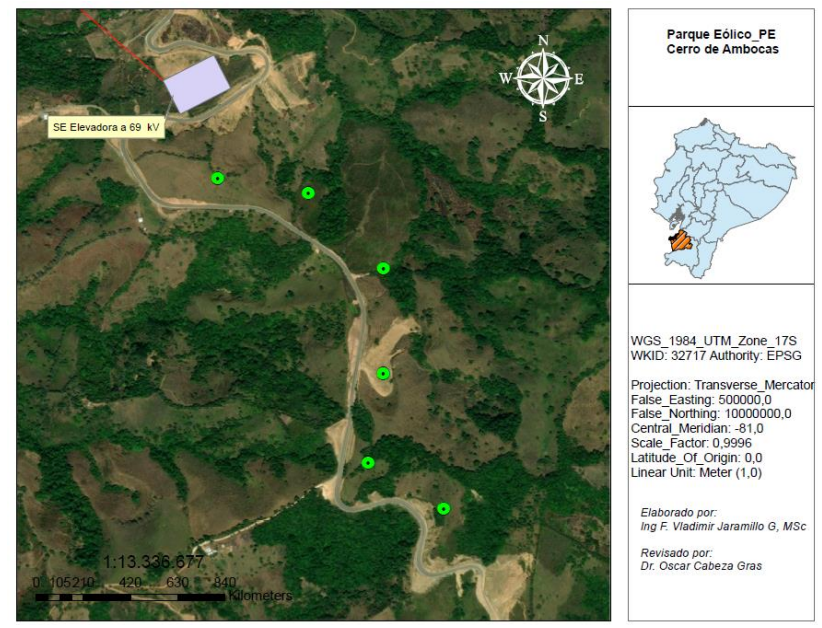

Fig. 1. Windmills location in Cerro de Ambocas.

With help of a micrometer precision GPS we locate each location in place for each wind turbine, being the obtained coordinates, after differential correction, summarized from $\mathrm{N}$ to $\mathrm{S}$ in Table I:

Table I. - Coordinates of the 6 wind turbines from $\mathrm{N}$ to $\mathrm{S}$.

\begin{tabular}{|c|c|c|}
\hline Wind mill & $x$ & $y$ \\
\hline A1 & 663310,574 & 9584320,47 \\
\hline A2 & 663495,652 & 9584289,44 \\
\hline A3 & 663649,668 & 9584135,61 \\
\hline A4 & 663649,305 & 9583920,61 \\
\hline A5 & 663618,139 & 9583736,37 \\
\hline A6 & 663772,258 & 9583643,97 \\
\hline
\end{tabular}

Now, we must analyse the primary wind energy, that will be transformed by the wind generators, process given by three ones: kinetic energy in mechanical and then in electrical by using NREL-Wind free software [6]. Wind Rose in the location chosen, shown in Figure 2, allows knowing that the wind direction is East all year, with very low fluctuations East North East. This permanent wind direction is an advantage for production and durability of turbines. Also, from the wind report, we know that maximum wind speed was $14.3 \mathrm{~m} / \mathrm{s}$ in July and minimum $5.8 \mathrm{~m} / \mathrm{s}$ in November as average in the last five years. Average speed is $9.7 \mathrm{~m} / \mathrm{s}$, more than enough for wind generation [4]. After choosing the most adequate turbine for the dominant winds with 1.5 MW power, which characteristic curve is shown in Figure 3, we simulate the influence of this installation in the charge flux of the area. We obtain that voltage level goes from minus $12 \%$ as actually to less than minus $4.5 \%$ being between the limits stablished by regulation of quality of del $\pm 5 \%$. In addition, we obtain a reduction in technical loss of 832 $\mathrm{kW} \cdot \mathrm{h}$. This last energy saving is due to the emplacement of the wind farm near the distribution station.

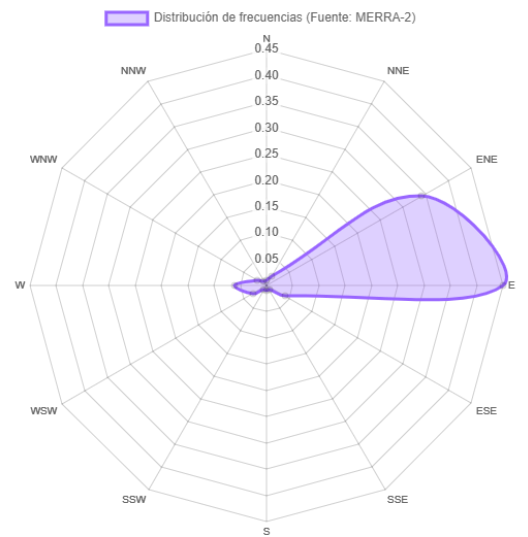

Figure 2. Wind Rose in the placement of the Wind Farm.

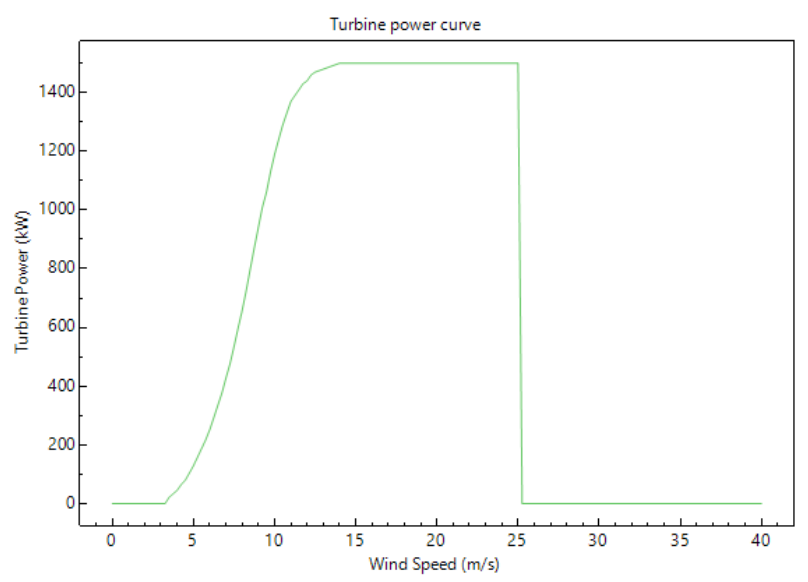

Fig. 3. Turbine power curve for the selected model.

The heigh of the axle box is of $85 \mathrm{~m}$ from land, and the rotor diameter is $77 \mathrm{~m}$. Wind quality at this heigh in the emplacement chosen will be very high due to its Poisseuille laminar regime most of the time. To calculate the energy generated by the WF it is necessary take into account a terrain rugosity coefficient, which varies depending on the land where the WF is placed, going the values from 0 to 0.4 [7]. In Table III we show the rugosity value for different terrains. In spite of the fact that our situation, in the hillside with nothing in front of the wind direction, we have chosen a conservative for rugosity in our work of 0.2 .

\begin{tabular}{|l|c|}
\hline \multicolumn{1}{|c|}{ Terrain type } & Rugosity Exp. \\
\hline Plane places with ice or grass & $0.08-0.12$ \\
\hline Plane places in the sea or near-shore & 0.14 \\
\hline Terrain with low accidents & $0.013-0.16$ \\
\hline Rustic areas & 0.2 \\
\hline Rough Terrain and woods & $0.2-0.26$ \\
\hline Very rough terrain and cities & $0.25-0.4$ \\
\hline
\end{tabular}

Table II. - Rugosity coefficient depending on the terrain type. 


\section{Production of the WF}

We must choose a value for the so called, turbulent coefficient due to secondary sources. We chose about $5 \%$ (too high probably) for our WF. This value is important to calculate the production of our wind turbines, because the trail effect implies turbulences in the rotor and so decrease of electrical production [8]. It is necessary to input this value in the computer program used for the calculation of the estimated power technical losses, here they have been estimated about an additional 5\% [9]. Now, using the NREL-Wind software, we can simulate the production of our WF, being the output given in Table III, where we present the estimated electrical energy production in the different months of the year as average, taking the wind data of the last 5 years. The annual production would be more than 52,000 MWh as obtained from the NREL-wind software simulation as observed in Table III, being the most productive months from June to September.

Table III. - Wind Energy Production in kWh during the months of a complete average year

\begin{tabular}{|c|r|r|r|r|r|r|r|}
\hline & Jan & Feb & Mar & Apr & May & Jun & Jul \\
\hline $\begin{array}{c}\text { Wind speed } \\
(\mathrm{m} / \mathrm{s})\end{array}$ & 7.8 & 7.6 & 7.9 & 8.8 & 9.9 & 13.2 & 14.3 \\
\hline MWh/day & 57,60 & 53,88 & 59,81 & 84,79 & 119,41 & 283,06 & 357,45 \\
\hline MWh/month & $1.785,70$ & $1.508,66$ & $1.854,21$ & $2.543,80$ & $3.701,64$ & $8.491,87$ & $11.080,83$ \\
\hline
\end{tabular}

\begin{tabular}{|c|c|c|c|c|c|c|}
\hline Aug & Sep & Oct & Nov & Dec & Average & Anual \\
\hline 13.8 & 13.0 & 7.7 & 5.8 & 6.8 & 9.7 & \\
\hline 322,18 & 270,74 & 55,49 & 24,32 & 38,59 & 143,94 & 52.560 \\
\hline $9.987,73$ & $8.122,23$ & $1.720,21$ & 729,49 & $1.196,24$ & 4393,55 & MWh/year \\
\hline
\end{tabular}

To determine the power factor we will use the usual equation given by [10]:

$$
F c=\frac{E G a(M W h)}{P G \operatorname{mom}(M W) * 8760(h)}
$$

Where:

\section{$\mathrm{EGa}=$ Generated Power \\ PGnom $=$ Nominal Power}

We obtain a power factor for our WF about 0.6, having been conservative in the calculation of the loose parameter.

\section{Connection of the WF}

To feed the national distribution system with the energy generated in the proposed WF, it is necessary a substation to elevate voltage from 34.5 to $69 \mathrm{kV}$ (i.e., from 16 to 20 MVA) to evacuate the generated electricity through a three wires transmission line of approximately $12 \mathrm{~km}$ from the WF to the electrical substation of Portovelo, as shown in Figure 5. The planned transmission line will be made with 500 MCM ACAR aluminium conductor wire.

Using the specialised software CYME CYMDIST, we can simulate the interconnection impact knowing the current fluxes. To do that, it is necessary to model the Power Electrical System (PES) of the Portovelo substation, as shown in Figure 6. Now, we proceed to model the WF electrical flux in the PES. To do that we must input the data from each wind tower as observed in Figure 7.
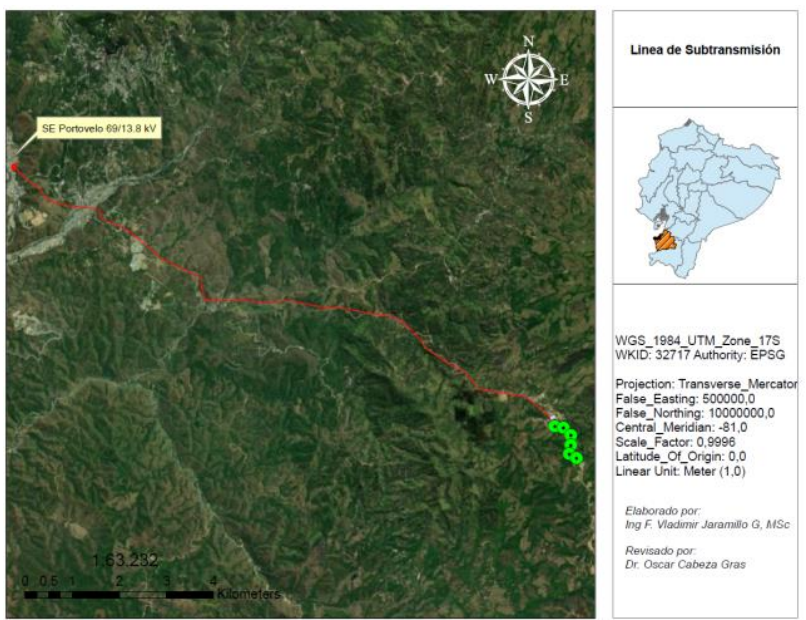

Fig. 5. Transmission line from the WF (dots in green) to the substation of Portovello (final red dot).

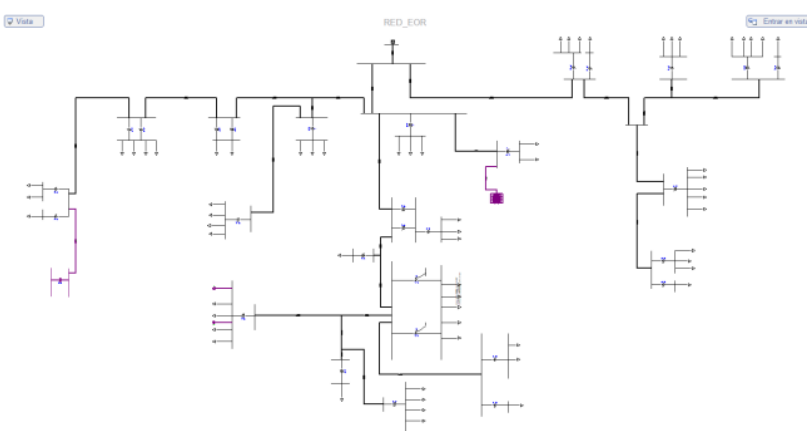

Fig. 6. Power Electrical System of Portovelo substation.

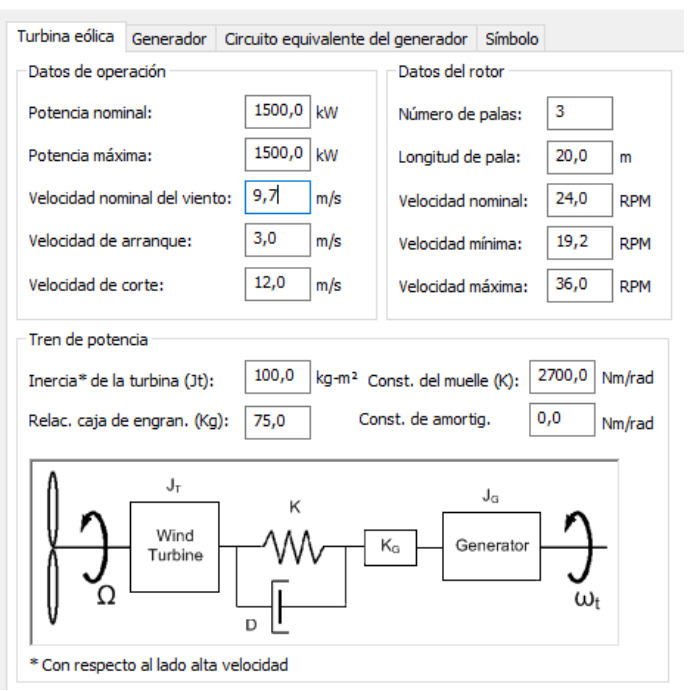

Fig. 7. Turbine data to be input in the system.

In addition, we must model the power generated by our system using variable wind speeds as shown in Figure 8. 


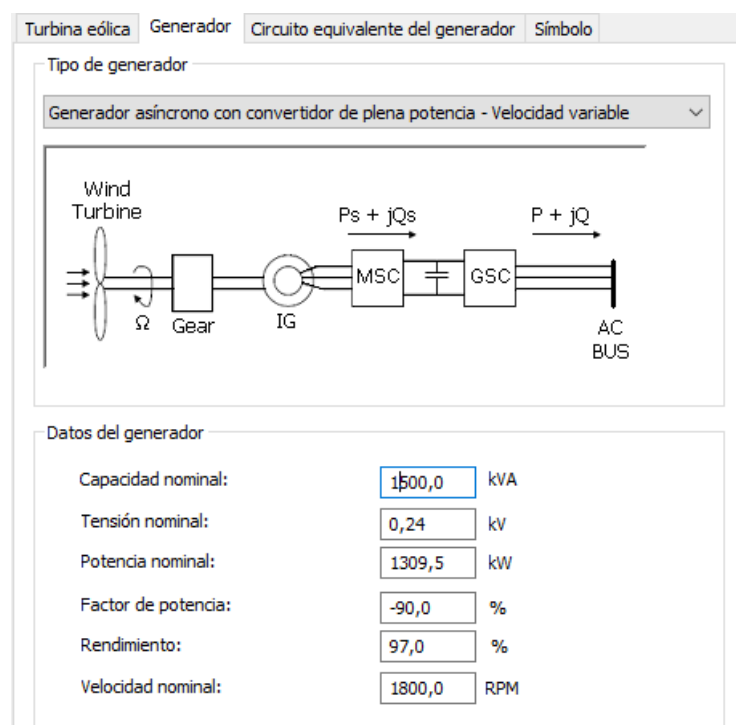

Fig. 8. Electrical generator data to input in the software.

We have planned an equivalent circuit to that of the base generator, using the maker data for it. This circuit for the induction generation proposed and the corresponding data for it appear in Figure 9:

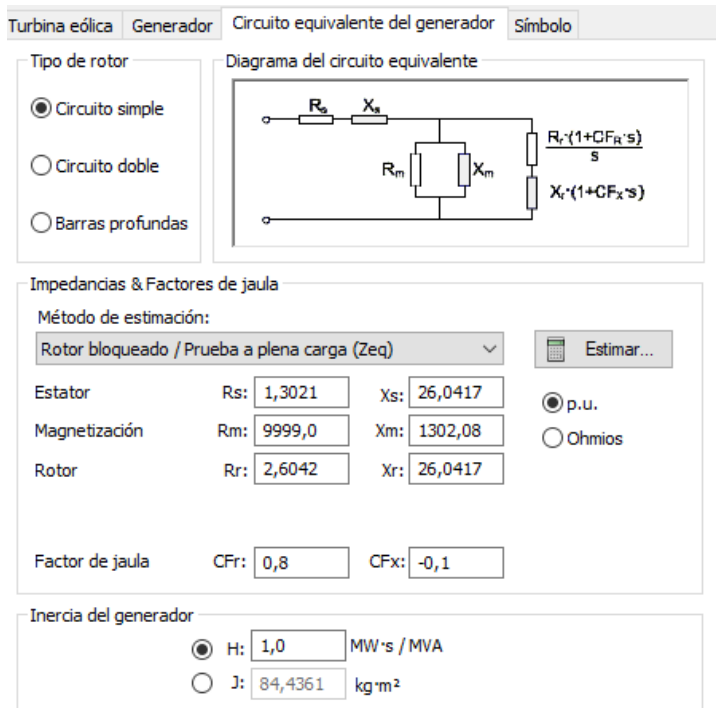

Fig. 9. Equivalent electrical circuit of the induction generator.

Finally, we can model the complete installation of the WF, the evacuation line and the connection in bar at $69 \mathrm{kV}$ to the Portovelo substation, as shown in Figure 10.

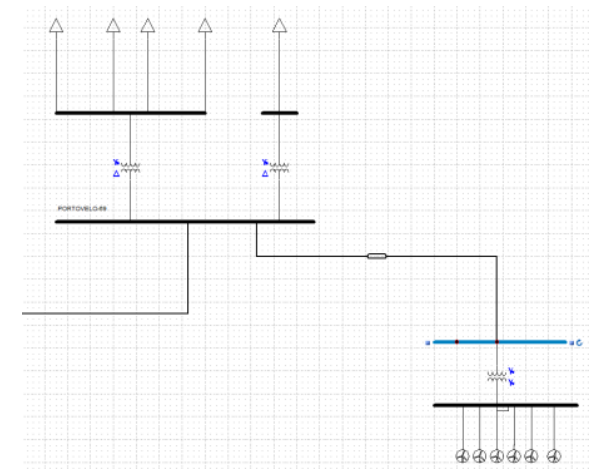

Fig. 10. Simulation of the WF connected to the PES.
One of the possible improvements of the planned WF is the replacement of the generator of each wind tower by a novel synchronous one using permanent magnets with variable speed and step. This means that the machine can generate a not fixed frequency, which will be converted to the standard frequency before connecting to the substation [11]. Among the most important characteristics of the new turbine are:

- It can regulate the active and reactive powers using a Back to Back converter.

- It is connected to the distribution system using a frequency converter.

- Synchronicity is obtained with a speed converter in the generator.

- Thus, it is not necessary a gear box.

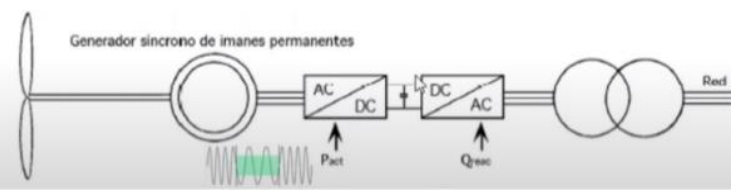

Fig. 11. Synchronous generator using permanent magnets.

\section{Quality improvement}

From the analysis of charge flux in the distribution system of Portovelo substation, we observe that the voltage level decreases from a $-12 \%$ to less than a $-4.5 \%$ which is withing the stablished values in que quality electrical system regulation of $\pm 5 \%$. In addition, the WF will reduce the technical loos from $8,209 \mathrm{~kW}$ to 7,313 $\mathrm{kW}$, which represents a decrease of about $11 \%$.

When analysing the voltage gaps due to the connection of the WF, using the same CYME CYMDIST software, we obtain a very similar minimum voltage increasing, less than a $5 \%$, which represents a low affection to the system. If we perform a short-circuit analysis for the 69 $\mathrm{kV}$ bar before and after of the WF connection, we can determine the change in the Type of Failure. The obtained results are summarised in Table V.

Table V. - Short-circuit analysis in kilo Ampere (kA)

\begin{tabular}{|l|c|c|}
\hline Type of Failure & $\begin{array}{c}\text { Current (kA) } \\
\text { Without WF }\end{array}$ & $\begin{array}{c}\text { Current (kA) } \\
\text { With FW }\end{array}$ \\
\hline Triphasic & 0.87 & 0.95 \\
\hline Line to Line & 0.87 & 0.95 \\
\hline Line to Earth & 0.52 & 0.53 \\
\hline
\end{tabular}

\section{Economic analysis}

This brief analysis has been done taking into account a useful life of the project of 20 years, which would be the minimum time the WF would be operative. Taking into account the power to be installed and the plant factor, we calculate the budget necessary to make this WF real, including: the transmission line of $12 \mathrm{~km}$ to the substation, the connection to the distribution system and all elements for the proper WF, which are summarised in Table VI. The total cost of the project is about 23.4 USD millions, while the estimated profits are about 5.26 USD millions per year. We must take into account some expenses as maintenance and operation costs of about 
0.55 USD millions per year and the exceptional maintenance at 10 years of operation with about 0.9 USD millions of costs. Making the total calculations of incomes and outcomes, we estimate a net profit before taxes of about 70.4 USD millions in the period of 20 years. Being the inversion return period lower than 5 years.

To finish this brief analysis, note that we obtain a Net Actual Value of about 33.8 USD millions, an Internal Return Tase if $25.5 \%$, and being the income-outcome relation of 9.3 , which is a very good value, taking into account that all above 1 means good business. This numbers indicates that the projected WF is viable and it would give a financial net profit higher than 3,5 USD million per year on average before taxes.

Table IV. Costs and incomes of our project

\begin{tabular}{|l|c|r|}
\hline \multicolumn{1}{|c|}{ Description } & Unity & \multicolumn{1}{c|}{ Proyect } \\
\hline Installed Power & $\mathrm{MW}$ & 10 \\
\hline Plant Factor & $\%$ & 60 \\
\hline Wind Farm with all components & USD/KW & 2,200 \\
\hline Substation connection & USD & $1,200,000$ \\
\hline Interconnection line & USD/Km & 17,000 \\
\hline O\&M variable & USD/MWh & 17 \\
\hline O\&M Fix & $\%$ investment & 2.50 \\
\hline Energy market prize & USD/MWh & 100 \\
\hline Emisions reduction certificate & USD & 486.89 \\
\hline
\end{tabular}

\section{Conclusions}

We have planned a wind farm, WF, of $10 \mathrm{MW}$ composed by six mills with $1.5 \mathrm{MW}$ power each near an existing road in Cerro de Ambocas. Loja (Ecuador). The capacity factor of the plant is 0.6 . which represents the possibility of very high production compared with majority of similar wind farms all over the world.

The bar voltage level in the electrical substation improves due to the injection of energy directly to the substation, which means a much better electricity quality system, minimising actual faults. The technical analysis shows that there is not any technical problem to install the WF. In addition, a brief economical study of the project gives net benefits higher than 3.5 USD million per year on average before taxes. So, it is a very good business as well its environmental and social positive implications. This last conclusion due to the improve of the electrical service quality for homes and industries in the area.

\section{References}

[1] Ali M. Eltamaly. A. Y.-K. (2021). Control and Operation of Grid-Connected Wind Energy Systems. Cham: pringer.

[2] Wind energy in Europe in 2019. Trends and statistics (2020). Wind Energy Organization. EDITOR: Colin Walsh. www.windeurope.org

[3] Ding. Y. (2020). Data Science Fig. 9. Turbina eólica incorporada al SEP

[4] Emeis. S. (2018). Wind Energy Meteorology. Garmish: Springer International Publishing.

[5] Harsh S. Dhiman. D. D. (2020). Supervised Machine Learning in Wind Forecasting and Ramp Event Prediction. Ahmedabad: Academic Press.

[6] Keyhani. A. (2019). Design of Smart Power Grid Renewable Energy Systems. New York: Wiley-Blackwell.

[7] García. M. A. (2017). Estudio del Potencial Eólico y Viabilidad de Parque Eólico en Andalucía. Sevilla: Escuela Técnica Superior de Ingeniería.

[8] Karimi. H. R. (2018). Structural Control and Fault Detection of Wind Turbine Systems. London: The Institution of Engineering and Technology.

[9] Kirkegaard. J. K. (2018). Wind Power in China: Ambiguous Winds of Change in China's Energy Market. Beijing: Routledge.

[10] Lorenzo Battisti. M. R. (2018). Wind Energy Exploitation in Urban Environment. Trento: Springer International Publishing.

[11] Cardemil, C.C. (2020). Energía Eólica: Sincronización a la red y topología de turbinas. Fundamentos de Energía Eólica (págs. 20-30). A Coruña: 3iE Energía 